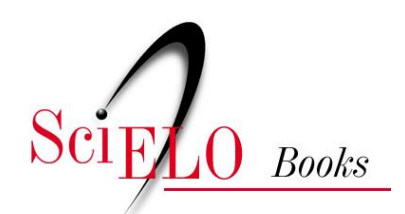

\title{
Experiencias de buenas prácticas \\ 4. Pantalla digital MIMIO en el área de comunicación con estudiantes con discapacidad intelectual de segundo de básica
}

\author{
Adriana Guachamín \\ Miriam Gallegos
}

\section{SciELO Books / SciELO Livros / SciELO Libros}

GUACHAMÍN, A., and GALLEGOS, M. Pantalla digital MIMIO en el área de comunicación con estudiantes con discapacidad intelectual de segundo de básica. In: GALLEGOS NAVAS, M., ed. La inclusión de las TIC en la educación de personas con discapacidad: relatos de experiencias [online]. Quito: Editorial Abya-Yala, 2019, pp. 75-85. ISBN: 978-9978-10-495-8. https://doi.org/10.7476/9789978104958.0007.

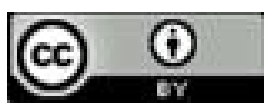

All the contents of this work, except where otherwise noted, is licensed under a Creative Commons Attribution 4.0 $\underline{\text { International license. }}$

Todo o conteúdo deste trabalho, exceto quando houver ressalva, é publicado sob a licença Creative Commons Atribição 4.0.

Todo el contenido de esta obra, excepto donde se indique lo contrario, está bajo licencia de la licencia $\underline{\text { Creative }}$ Commons Reconocimento 4.0. 


\section{5}

\section{Recursos utilizados}

Los recursos utilizados en la realización la propuesta de capacitación son:

- Laboratorio Computacional.

- Software de Ofimática.

- Internet con acceso libre a redes sociales.

- Pizarrón de tiza líquida.

- Marcadores de tiza líquida.

\section{Pantalla digital MIMIO en el área de comunicación con estudiantes con discapacidad intelectual de segundo de básica}

"Todos tenemos la esperanza de que el mundo pueda ser un lugar mejor donde vivir y la tecnología puede colaborar para que ello suceda"

(Tim Berners Lee)

Fundación individualizada para Niños, Niñas y Adolescentes EINA

Ecuador

Quito

Responsable: Adriana Guachamín

Gestores de la práctica: 42 estudiantes de segundo año de Educación Básica con discapacidad intelectual, Director de la institución y 12 docentes

La buena práctica docente giró en torno al desarrollo del plan micro curricular usando varias aplicaciones informáticas motivadoras para los estudiantes, con esta experiencia, se desplegó un gran abanico de posibilidades de estrategias didácticas para trabajar en Matemática, Comprensión Lectora, Ciencias e Historia, desarrollando aprendizajes útiles para los estudiantes.

\section{Motivación}

La Fundación Individualizada Para Niños, Niñas y Adolescentes EINA, es una institución ubicada en el Distrito Metropolitano de Quito sector Pusuqui, es una entidad sin fines de lucro que brinda atención 


\section{6}

personalizada a niños, niñas y jóvenes con discapacidad intelectual, la unidad educativa cuenta con los niveles de educación inicial, básica y formación profesional, su finalidad es la inclusión socio-laboral de sus estudiantes.

La institución ofrece educación individualizada, su propuesta curricular institucional, está basada en la propuesta curricular del Ministerio de Educación, en la misma se incentiva el uso de la tecnología tanto a estudiantes como profesores con miras a potenciar el proceso de aprendizaje de los estudiantes.

El aprendizaje de las personas con discapacidad intelectual, permite a los docentes mejorar su práctica educativa haciendo usos de variadas y creativas formas de enseñar. Los desafíos a los que nos vemos comprometidos los docentes es el de mantener la motivación de los estudiantes y evitar el rechazo y la frustración a ciertos actividades de orden cognitivo.

Por decisión institucional, se colocaron pantallas digitales interactivas "Mimio", como un mecanismo de equiparación de oportunidades de aprendizaje, de esta manera eliminar las barreras del aprendizaje de los estudiantes a través del uso de la dispositivos tecnológicos.

\section{Objetivo}

Apoyar el aprendizaje de los estudiantes en las diferentes áreas curriculares a través de la utilización de recursos didácticos y tecnológicos.

\section{Objetivos específicos}

- Elaborar una micro planificación curricular que responda a las necesidades del estudiante incorporando el uso de las TIC.

- Transformar la hora de clase tradicional en un espacio lúdico y divertido mediante el uso de recursos tecnológicos interactivos.

- Involucrar a los padres de familia en el uso de herramientas tecnológicas para que exista un refuerzo académico en el hogar. 


\section{7}

\section{Desarrollo de la experiencia}

Esta experiencia dio inicio con la familiarización por parte de los docentes en el uso y beneficios de varias herramientas tecnológicas y software Mimio Teach, posteriormente se desarrolló un proceso de capacitación a las familias para informarles de las estrategias de aprendizaje a desarrollar para que de esta manera apoyen a sus hijos en el hogar.

Un punto importante fue el proceso de planificación microcurricular a través de las destrezas con criterio de desempeño que den respuesta a la diversidad de ritmos y estilos de aprendizaje, intereses, entre otros; que potencien al máximo las habilidades personales.

Durante la prueba de manejo de la pizarra interactiva, se observó el entusiasmo de los estudiantes por aprender poco a poco, se evidenció mayor disposición para el aprendizaje de las matemáticas, estudios sociales y comunicación.

La pantalla digital Mimio es un producto muy flexible y permite a los docentes elaborar sus propios recursos didácticos y formar parte de una red de profesores que comparten infinidad de recursos, es una plataforma para trabajar en paralelo con otros programas. El kid Mimio funciona con un computador, un proyector, un pizarrón que sirva de pantalla, un marcador óptico con su receptor y el software Mimio Studio. Estos equipos permiten que el docente proyecte sobre el pizarrón la clase que previamente planificó y que tanto él, como los estudiantes puedan trabajar sobre la proyección con el lápiz óptico que es a la vez un marcador tradicional y un mouse inalámbrico.

Si bien, dichos equipos presentan muchas bondades, son el trabajo y la creatividad del docente los que hacen de esta herramienta una posibilidad sin límites para innovar en la enseñanza día a día. 


\section{8}

Figura 30

Pantalla Mimio

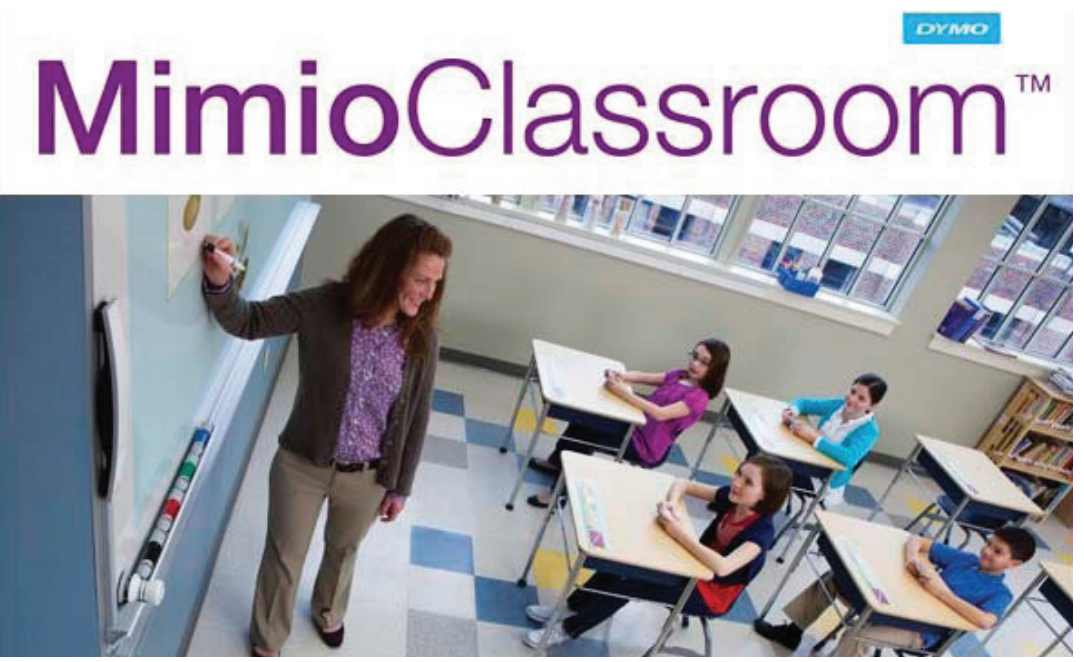

Fuente: MimioClassroom. Recuperado de https://goo.gl/N4uaVV

Figura 31

Utilitarios Pantalla Mimio

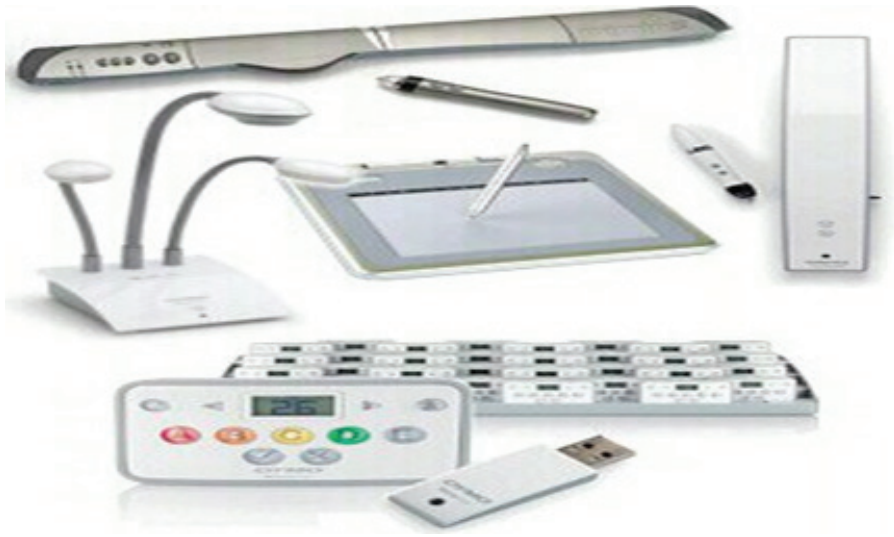

Fuente: TecnoEdu. Recuperado de https://goo.gl/LSczZ9 
Los programas utilizados como apoyo al aprendizaje de las diferentes asignaturas en la plataforma de la pantalla fueron:

Sebran's ABC. Es un programa gratuito que cuenta con doce juegos para que los más pequeños, de 4 a 9 años que se diviertan mientras aprenden. Incluye juegos muy variados y entretenidos, juegos de memoria, de palabras, de matemáticas, de abecedario. Las actividades que se presentan son lúcidas las cuales llaman la atención del niño, haciendo un aprendizaje divertido.

Figura 32

Software Sebran

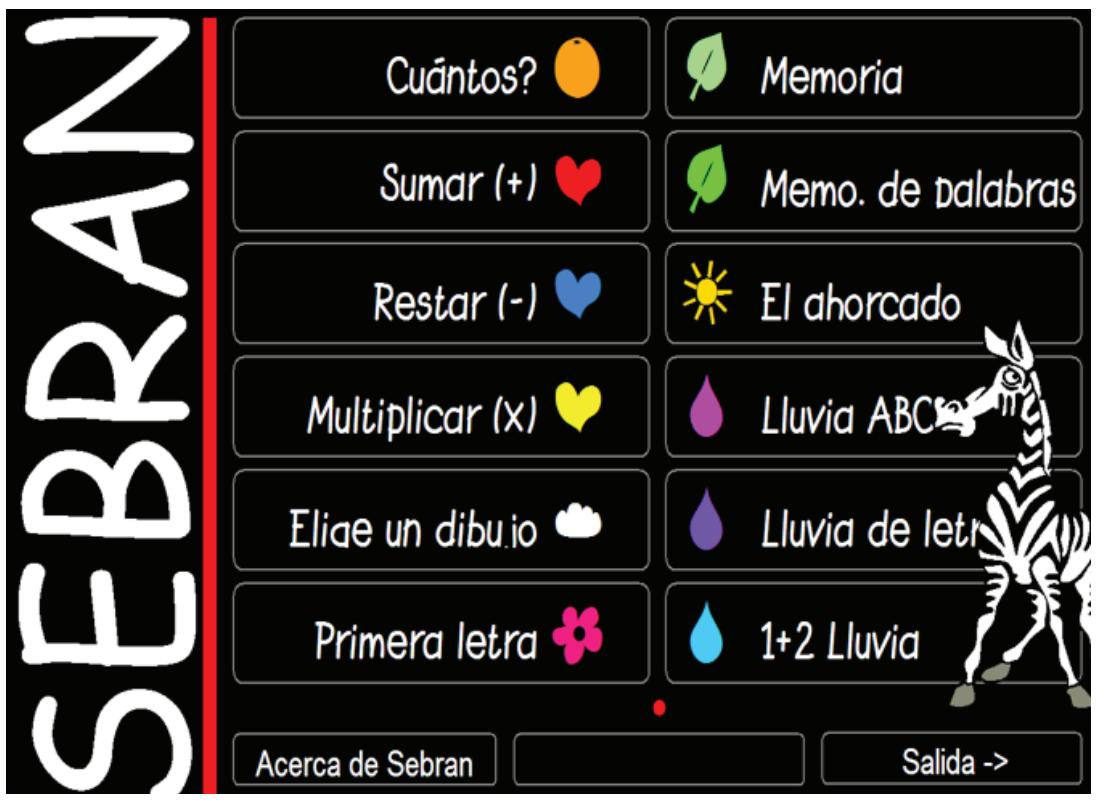

Fuente: Potal Programas. Recuperado de: https://goo.gl/8kDrtZ

Mini Sebran. Es un programa de juegos educativos para niños de 2 a 6 años. Incluye ocho actividades diversas, entre las que propone ejer- 


\section{0}

cicios con siluetas, juegos sencillos para familiarizarse con los colores, los números y las letras.

Minisebran, es una colección de ocho juegos muy sencillitos para que niños pequeños, aprendan mientras se entretienen. Los juegos, o mejor dicho ejercicios, están orientados a que el niño descubra los números, las letras y aprenda a usar el teclado y el ratón.

Figura 33

Software Mini Sebran

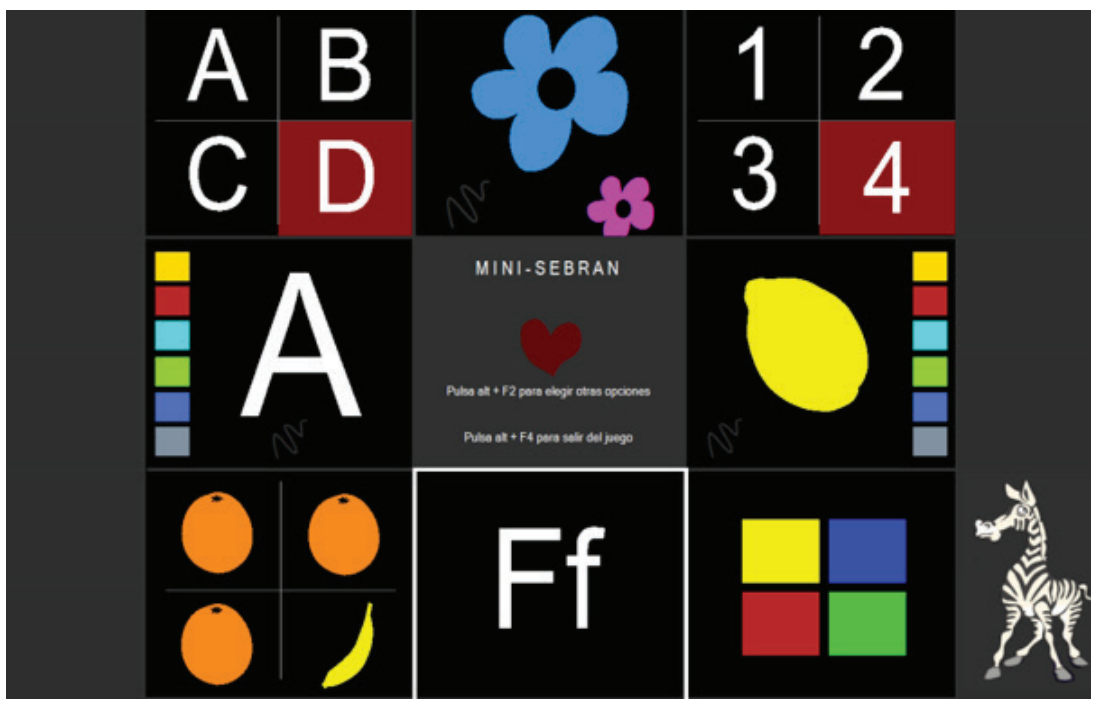

Fuente: Seterra. Recuperado de https://goo.gl/XndV8z

Proyecto Aprender. Presenta variadas e interesantes actividades relacionadas a diferentes temáticas curriculares.

Canta Letras. Es un software educativo para la enseñanza de la lectura y escritura.

El Toque Mágico. Este programa tiene por objeto el desarrollo de nociones y conceptos previos a la escolarización, tales como el lenguaje, 


\section{1}

los números, la orientación espacial y temporal; de manera entretenida para el niño.

Figura 34

Ejemplo de Software de Proyecto Aprender

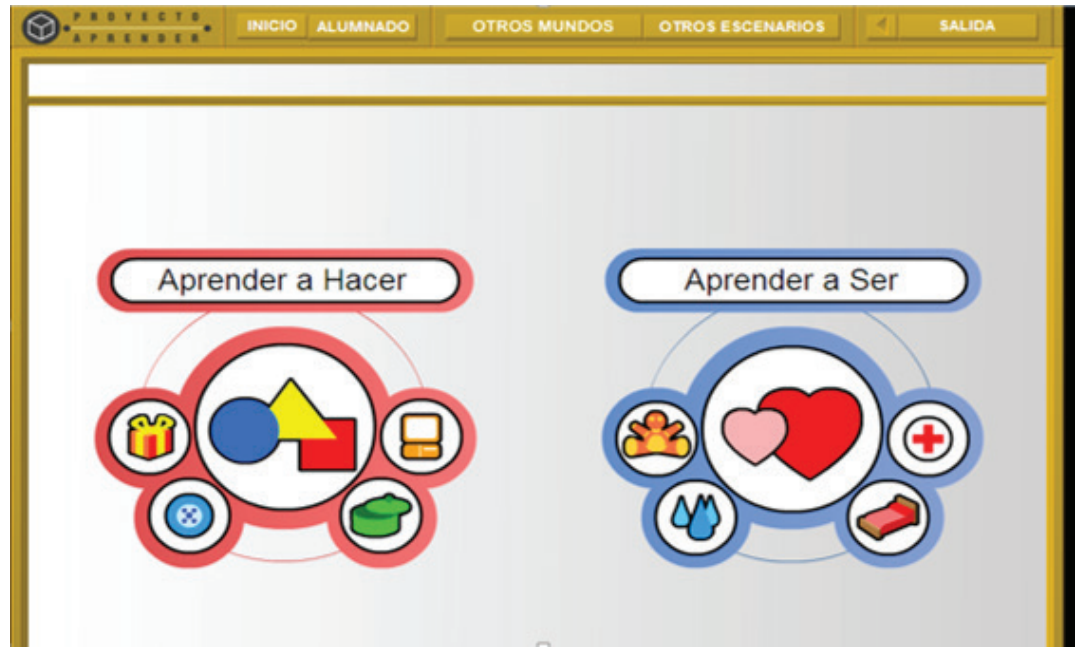

Fuente: Informática para educación especial. Recuperado de https:/goo.gl/d9FWEi

Los diferentes programas se utilizaron para reforzar los siguientes contenidos académicos:

- Funciones básicas: lateralidad, temporalidad, espacialidad.

- Colores, formas, tamaños.

- Números, operaciones básicas.

- Vocales, abecedario, sílabas, palabras

Si bien todas las actividades desarrolladas con los programas antes mencionados forman parte de la planificación microcurricular también, se las refuerza en el plan individualizada de esta manera también se incentiva su uso en el hogar. 


\section{2}

\section{Figura 35}

\section{Estudiantes trabajando con la pantalla Interactiva Mimio}
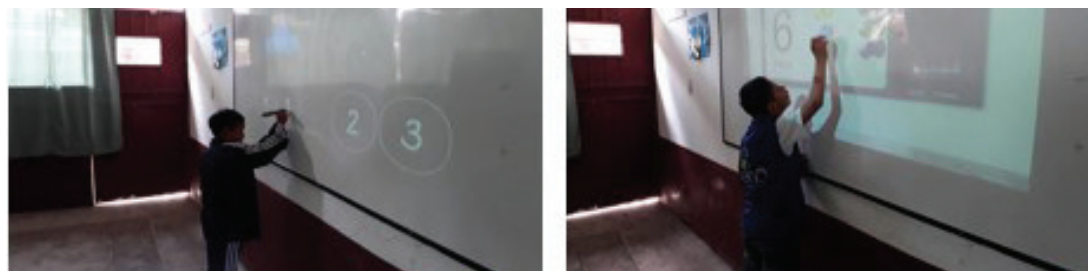

Foto: Adriana Guachamín (2016)

\section{Logros obtenidos}

Los resultados alcanzados en esta experiencia nos arrojan datos sobre los avances en la comprensión y memoria presentan además mayor motivación para el aprendizaje.

\section{Tabla 4 \\ Logros obtenidos}

Con esta metodología lúdica se logró que los estudiantes aprendan con facilidad y que no tengan a participar de manera espontánea.

\begin{tabular}{|l|l|}
\hline \multicolumn{1}{|c|}{ Áreas } & \multicolumn{1}{c|}{ Logros } \\
\hline Matemáticas & $\begin{array}{l}\text { Jugar con los conjuntos y los números lo hacen de una for- } \\
\text { ma divertida. } \\
\text { Reconocimiento de colores y tamaños en los objetos trabaja- } \\
\text { dos durante la planificación. } \\
\text { Ubicación espacial y temporal, lateralidades y nocio- } \\
\text { nes básicas. }\end{array}$ \\
\hline $\begin{array}{l}\text { En lenguaje y } \\
\text { comunicación }\end{array}$ & $\begin{array}{l}\text { Lectura de pictogramas. } \\
\text { Reconocimiento de secuencias comprensiva, reconocen soni- } \\
\text { dos con la vocal y el significado, etc. } \\
\text { Comunicación dialogo es más espontáneo. }\end{array}$ \\
\hline Estudios sociales & Reconocimiento de las regiones del país, división política. \\
\hline Ciencias Naturales & Conozcan la flora y fauna del Ecuador \\
\hline
\end{tabular}

Fuente: Adriana Guachamín (2016) 


\section{3}

Cuantitativamente el uso de las herramientas tecnológicas ha permitido que actualmente 42 estudiantes de segundo año de básica logren establecer un aprendizaje significativo por medio de la utilización de las pantallas digitales.

Los estudiantes a través de la pantalla digital se sienten motivados y se logra captar y extender sus períodos de atención debido a los sonidos, imágenes en movimiento y otros elementos. Las actividades que deben ejecutar en cada programa les permite desarrollar determinada destreza hasta lograr un objetivo, para luego pasar a otro que representa un reto mayor; de esta forma van de lo simple a lo complejo.

Por otra parte, un aporte muy significativo es que además de ayudar a desarrollar o mejorar destrezas en diferentes niveles y áreas; está el hecho de que disfrutan de la actividad y desarrollan un nivel de competencia y valía a través de los logros que ellos experimentan al superar los retos que se les plantea, esto sin duda, aporta a su bienestar emocional y su autoestima.

El uso del Mimio y los programas nos ha permitido observar no solo resultados medibles sino que ha logrado generar un ambiente diferente en el entorno escolar ya que ha motivado a los docentes a la investigación y uso de herramientas tecnológicas, a la innovación constante de los contenidos y metodologías de enseñanza y una mayor motivación por parte de los estudiantes.

Adicionalmente se ha evidenciado una reducción en el tiempo promedio de adquisición de la lecto-escritura básica y operaciones matemáticas de suma y resta en los estudiantes con discapacidad intelectual que tuvieron el apoyo de Mimio en este proceso. 


\section{4}

Figura 36

Tiempo promedio de adquisición de la lecto escritura básica y operaciones matemáticas de suma y resta

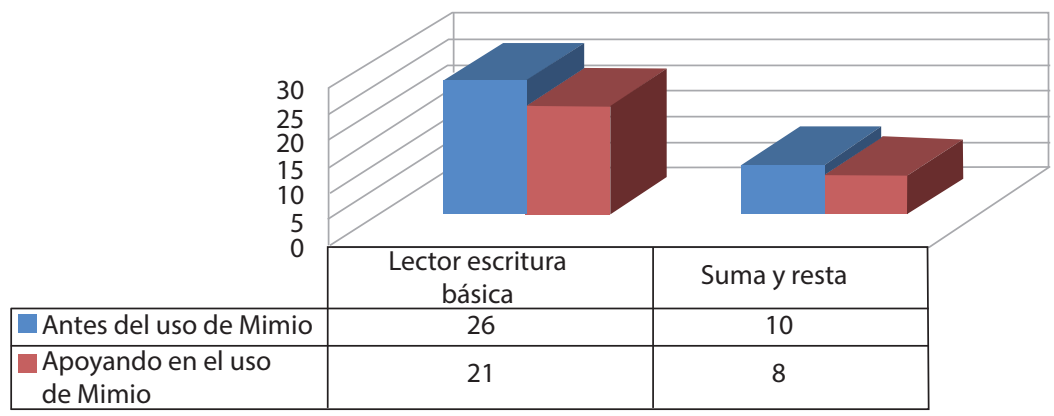

Fuente: Adriana Guachamín (2016)

Otro resultado obtenido es el incremento en el gusto de los estudiantes por las materias consideradas de más difícil comprensión y el alto índice de aceptación y gusto de la hora de Mimio. Este resultado más allá de expresarse cuantitativamente se aprecia en el deseo diario de los estudiantes por aprender.

Figura 37

Agrado por acudir a cada asignatura/10

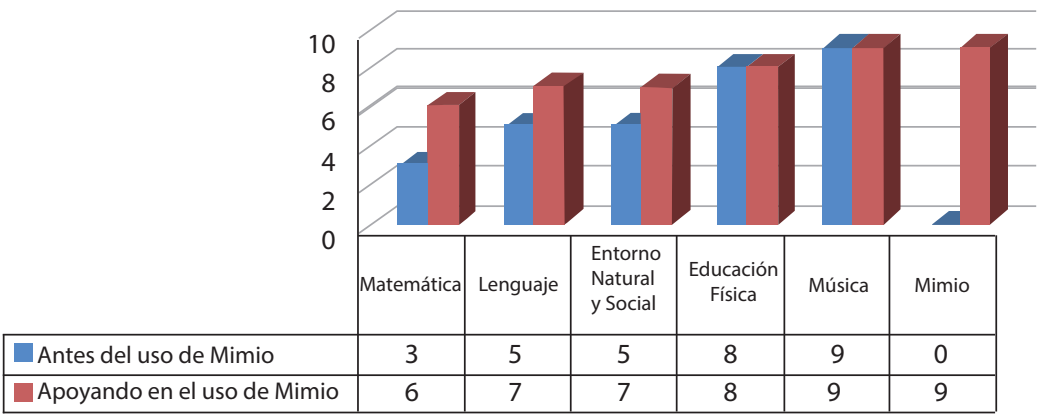

Fuente: Adriana Guachamín (2016) 
En la figura anterior se observa hay un incremento en el sentimiento de agrado por las materias que anteriormente eran rechazadas por los estudiantes.

\section{5. ¿Estudiantes aburridos o propuesta pedagógica poco motivadora? - Experiencia de inclusión significativa de las TIC en los procesos de enseñanza y aprendizaje}

"La verdadera educación consiste en obtener lo mejor de uno mismo. ¿Qué otro libro se puede estudiar mejor que el de la Humanidad?"

(P. Freire)

Escuela Normal Víctor Mercante-Nivel Superior

Argentina

Córdoba

Responsable: Lamberti Evelina Mariel

Gestores de la práctica: equipo directivo de la institución educativa, compuesto por: Prof. Petrucci Marcela - Directora y Lic. Tesan Luciana - Vicedirectora

Para enfrentar las necesidades de aprendizaje de un grupo de estudiantes ( 4 estudiantes con discapacidad intelectual 1 estudiante con Síndrome de West) esta práctica resalta dos aspectos de la dinámica pedagógica. En ese sentido, la práctica docente buscó promover y estimular en los estudiantes la resolución de problemas en el contexto real, así como, mejorar su capacidad de expresión oral, y la comprensión lectora a través del uso de varios dispositivos tecnológicos que se constituyeron en apoyos efectivos en el logro de los objetivos propuestos.

\section{Motivación}

De acuerdo a lo que establece la Ley de Educación Nacional, en el art 41: La Educación Especial es la modalidad del Sistema Educativo destinada a asegurar el derecho a la educación de las personas con discapacidades, temporales o permanentes, en todos los niveles y modalidades del Sistema. Se rige por el principio de inclusión y brinda atención educativa a todas aquellas problemáticas específicas que no puedan ser abordadas por la educación común (Congreso de la Nación Argentina, 2006, p. 9). 